\title{
Perfil profesional das mulleres no sector financeiro de Galicia
}

\author{
Women'sprofessionalprofile in theGalicianfinancial sector \\ M Dolores Castro Pais, M ${ }^{\mathrm{a}}$ Josefa Mosteiro García, Ana Ma Porto Castro \\ Universidade de Santiago de Compostela
}

\begin{abstract}
Resumen
O principal obxectivo do estudo é coñecer a situación real que teñen as mulleres no sector financeiro a través da análise de variables persoais (idade, nivel de estudos,...) e profesionais (cargo, nivel profesional, categoría, antigüidade, persoas que dirixen,...). A mostra está formada por un total de 979 empregados/as de 226 oficinas bancarias situadas en Galicia. Os resultados obtidos móstrannos que homes e mulleres comparten un mesmo espazo laboral pero non o fan de forma equitativa, xa que a maioría das oficinas están xestionadas por homes; ademais as mulleres necesitan maior formación e tempo para alcanzar un posto de responsabilidade.
\end{abstract}

Palabras clave: [xénero, perfil profesional, sector financeiro].

\begin{abstract}
The mainaimofthestudy is to knowthe real situationthatoccupythewomen in thefinancial sector throughtheanalysisofpersonal variables (age, levelofstudies,...) and professional (ones, category,proffesionallevel, seniority, peopleundertheirdirection,...). The sample is formedby a total of 979 employeesof 226 bankingoffices in Galicia. The resultsobtainedshowthatmen

and

womensharethesameworkspacethere are notfairness, sincemostoffices are managedbymenmoreoverwomenneed more training and time to reach a positionofresponsibility.
\end{abstract}

Keywords: [gender, professionalprofile, financial sector].

\section{Introdución}

O papel social desenvolvido polas mulleres na sociedade actual é ben distinto ao protagonizado en tempos pasados (Echebarría e Larrañaga, 2004).En España, ata que se implanta a Lei de relacións laborais de 1976 non desaparece o permiso do marido como requisito legal necesario para que a esposa puidera exercer o su dereito ao traballo. Esta incorporación ao mercado laboral constitúe un dos fenómenos máis característicos do século $\mathrm{XX}$ que provoca un aumento significativo e constante tanto da participación laboral das mulleres como do seu nivel formativo.

O avance logrado polas mulleres nos países desenvolvidos é o resultado de séculos de loita continuada traducida en importantes cambios en materia lexislativa, educativa, social e económica.

O seu acceso á educación conseguiuse de forma xeneralizada e a súa participación no mercado de traballo aumentou de xeito significativo nas últimas décadas. Sen embargo, o ámbito laboral segue a caracterizarse por un importante androcentrismo (Barberá, 2000) e por manter unha estrutura xerárquica característica das relacións de xénero das sociedades patriarcais. Aínda que moitas mulleres conseguiron introducirse en determinados niveis das organizacións, non logran ocupar as verdadeiras posicións de poder explícito (Valcárcel, 1997). Os índices de segregación laboral de xénero horizontal e sobre todo vertical coa concentración das mulleres en determinados sectores e postos, apoian esta afirmación. A igualdade de oportunidades entre os sexos quedou legalmente establecida, pero persiste a desigualdade de condicións, marcada polos costumes sociais e culturais, desigualdades que afectan principalmente aos roles que mulleres e homes exercen na profesión e na familia, e á posición que unhas e outros ocupan dentro dunha mesma organización, en relación co poder (Osca e López-Sáez, 1994). Estes aspectos centranestainvestigación que aborda, sobre todo, a masculinización dos postos de dirección como un síntoma máis da discriminación que sofren as mulleres na súa traxectoria profesional.

O principal obxectivo deste estudo é coñecer a situación real das mulleres dentro do sector financeiro da Comunidade Autónoma de Galiciae comprobar se a distribución das mulleres e dos homes nos grupos profesionais, definidos por convenio, no sector financeiro é proporcional e igualitaria. Ademais de estudar a posición das mulleres dentro da organización, realizase unha descrición do seu perfil a través da análise de variables persoais (idade e nivel de estudos) e profesionais (cargo, nivel profesional, categoría, antigüidade, número de persoas que dirixen).

\section{Participantes}

\section{Método}

O universo muestral corresponde ao total de traballadoras/es de banca que prestan os seus servizos en postos de dirección, subdirección ou de administración en oficinas bancarias de Galicia. A mostra obxecto de estudo esta formada por 979 empregadas/os de banca, 374 mulleres e 605 homes, dun total de 226 oficinas bancarias distribuídas xeograficamente, entre as catro provincias da Comunidade Autónoma de Galicia como se mostra na figura 1: 


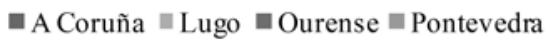

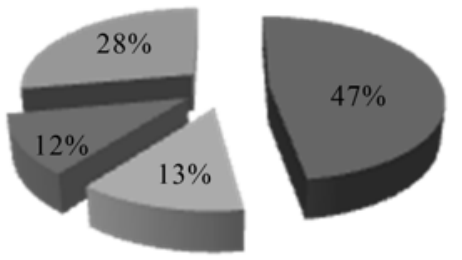

Figura 1. Distribución xeográfica da mostra segundo o sexo

\section{Instrumento}

Para a recollida de información solicitouse as 226 entidades bancarias con sede en Galicia que cumprimentasenun cuestionario que se distribuíu persoalmente, por correo ordinario e on line.

\section{Variables}

As variables obxecto de estudio son aspersoaisidade e nivel de estudos; as variables profesionais estudadas son: cargo, nivel profesional, categoría, antigüidade, persoas que dirixen.

\section{Análise de datos}

Mediante o paquete estatístico SPSS levouse a cabo unha análise descritiva a través do cálculo de frecuencias e porcentaxes para cada unha das variables consideradas na investigación.

\section{Resultados}

A continuación presentamos os resultados derivados da análise realizada para cada unha das variables obxecto de estudo.

\section{Variables persoais}

A idade é unha das características persoais máis determinantes da situación de mulleres e homes no mercado de traballo; como se observa na figura 2 , a incorporación da muller ao mercado de traballo nas últimas décadas provoca unha similitude de representación nas idades máis temperás con respecto aos seus compañeiros varóns, cunha clara diminución da presenza feminina a partires dos 45 anos.

\section{" Mulleres $\mathbf{m}$ Homes}

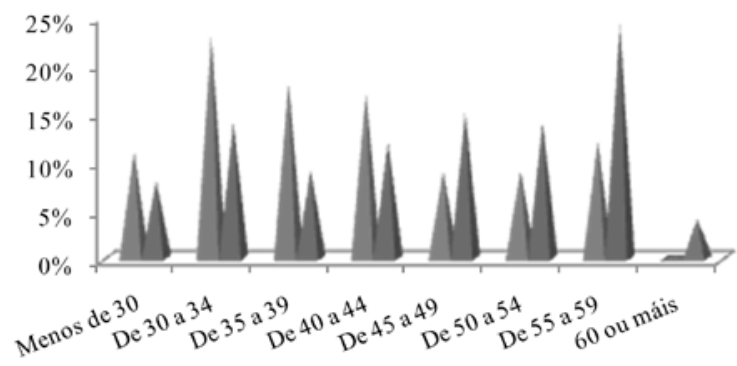

A formación académica de mulleres e varóns tamén mostra tendencias ben diferenciadas;a porcentaxe de homes con estudos primarios/FPI e secundarios FPII é maior que a das mulleres, pola contra, a medida que ascendemos no nivel académico a porcentaxe de mulleres mellor formadas aumenta de xeito significativo. Mais do $66 \%$ das mulleres teñen estudos universitarios fronte ao $45 \%$ de varóns.

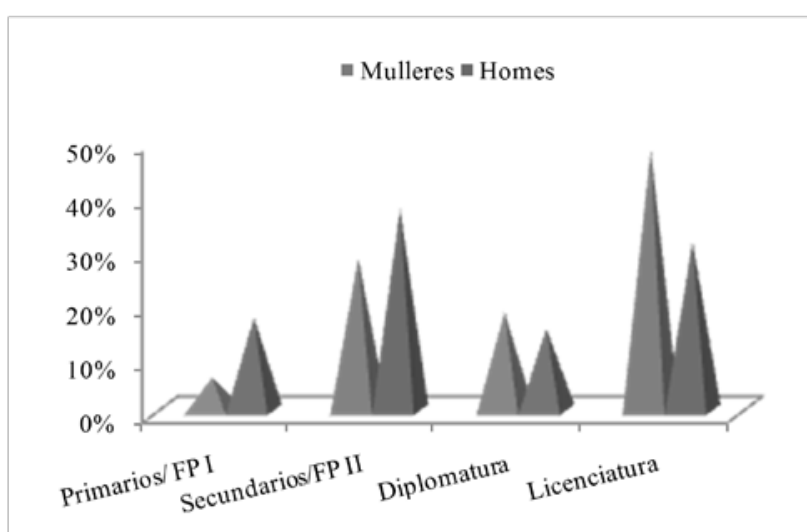

Figura 3. Distribución da mostra segundo nivel de estudos por sexo

\section{Variables profesionais}

A pesar de que contamos cunha mostra de mulleres con maior formación académica que os seus compañeiros varóns, se analizamos a distribución de unhas e outros nos distintos postos de traballo observamos un desequilibrio entre ambos sexos (Véxase Figura 4). A maior parte das mulleres concéntranse nos postos administrativos $(64,44 \%)$ e só un $9 \%$ ocupan postos de dirección fronte ao $32 \%$ de homes.

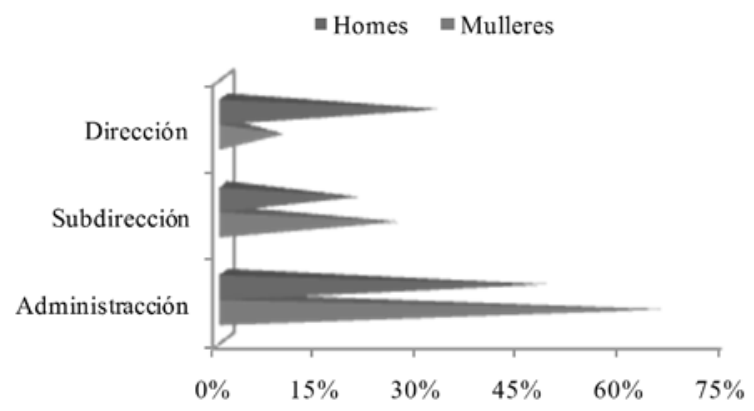

Figura 4. Distribución da mostra por cargo segundo o sexo

Esta mesma tendencia obsérvase na análise da distribución da mostra entre os niveis profesionais da banca; tendo en conta que o Nivel I se vincula cuns maiores ingresos, só o 13\% das mulleres teñen un nivel V ou inferior fronte ao $37 \%$ dos seus compañeiros varóns. A maioría delas, mais do $60 \%$, están entre os niveis VII ou superiores; a porcentaxe de homes neste rango, como se pode observar na figura 5, é a metade (33\%). 


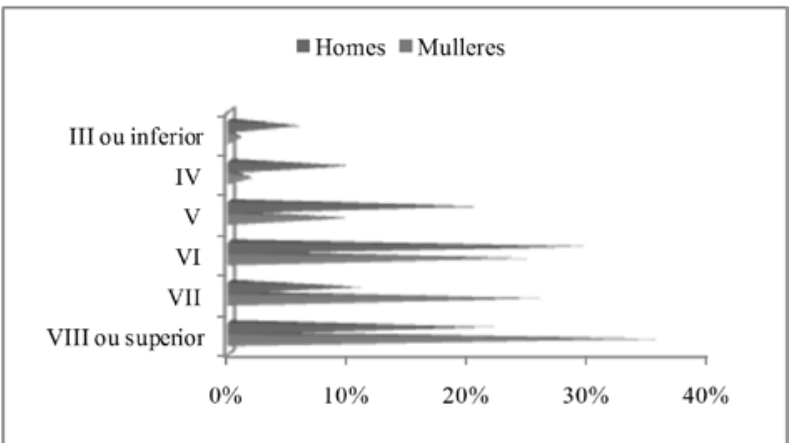

Figura 5. Distribución da mostra por nivel profesional segundo o sexo

Se realizamos a análise por cargo, as diferenzas agudízanse: máis do 92\% das mulleres que ocupan postos de subdirección teñen unha categoría profesional VI ou superior fronte ao $60 \%$ dos seus compañeiros varóns (Véxase Táboa 1).

Táboa 1.Categoría profesional das/os Subdirectoras/es

\begin{tabular}{lcc}
\hline Niveis & Mulleres & Homes \\
\hline III ou inferior & $1 \%$ & $4 \%$ \\
IV & $2 \%$ & $10 \%$ \\
V & $5 \%$ & $26 \%$ \\
VI ou superior & $92 \%$ & $60 \%$ \\
\hline
\end{tabular}

Nos postos de dirección, só o 38\% das mulleres teñen un nivel profesional de $\mathrm{V}$ ou superior fronte o $63 \%$ de directores (Véxase Táboa 2).

Táboa 2.Categoría profesional das/os Directoras/es

\begin{tabular}{lcc}
\hline Niveis & Mulleres & Homes \\
\hline III ou inferior & $3 \%$ & $13 \%$ \\
IV & $6 \%$ & $19 \%$ \\
V & $29 \%$ & $31 \%$ \\
VI ou superior & $63 \%$ & $37 \%$ \\
\hline
\end{tabular}

En canto a antigüidade na empresa de mulleres e homes que ocupan postos de dirección e subdirección nas oficinas bancarias, pódese observar que a incorporación da muller ao ámbito laboral é tardía. Máis do 90\% das mulleres que ocupan postos de dirección ou subdirección incorporáronse á empresa nos últimos 20 anos, mentres que tan só o 7\% delas teñen unha antigüidade de 20 anos ou máis fronte ao $40 \%$ dos seus compañeiros varóns (Véxase Táboas 3 e 4).

Táboa 3. Antigüidade na empresa das/os Subdirectoras/es

\begin{tabular}{lcc}
\hline Anos & Mulleres & Homes \\
\hline 30 ou máis & $7,14 \%$ & $34,40 \%$ \\
De 20 a 29 & $1,02 \%$ & $12,80 \%$ \\
De 15 a 19 & $16,33 \%$ & $17,60 \%$ \\
De 10 a 14 & $7,14 \%$ & $7,20 \%$ \\
De 5 a 9 & $22,45 \%$ & $7,20 \%$ \\
Menos de 5 & $45,92 \%$ & $20,80 \%$ \\
\hline
\end{tabular}

Táboa 4. Antigüidade na empresa das/os Directoras/es

\begin{tabular}{lcc}
\hline Anos & Mulleres & Homes \\
\hline 30 ou máis & $2,86 \%$ & $21,35 \%$ \\
De 20 a 29 & $2,86 \%$ & $11,98 \%$ \\
De 15 a 19 & $20 \%$ & $23,96 \%$ \\
De 10 a 14 & $11,43 \%$ & $4,17 \%$ \\
De 5 a 9 & $31,43 \%$ & $13,02 \%$ \\
Menos de 5 & $31,42 \%$ & $25,52 \%$ \\
\hline
\end{tabular}

Se analizamos o número de persoas que lideran, comprobamos que, en xeral, as directoras e as subdirectoras teñen ao seu cargo menos empregados que os seus compañeiros varóns. Só o $8 \%$ de directoras dirixen grupos de máis de 10 persoas fronte ao $15 \%$ de directores.

- Mulleres $\approx$ Homes

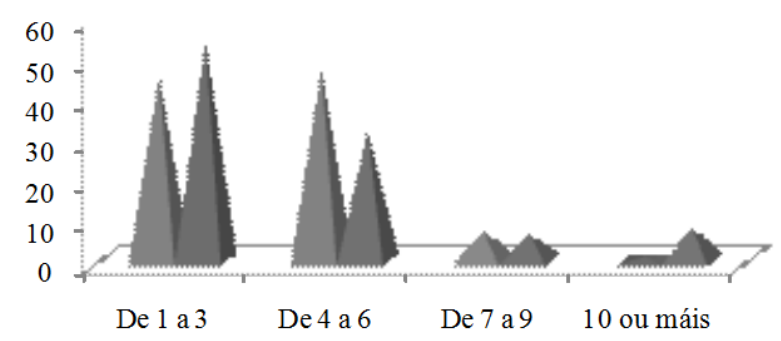

Figura 6. Número de persoas subordinadas (Subdirectoras/es)

"Mulleres $\square$ Homes

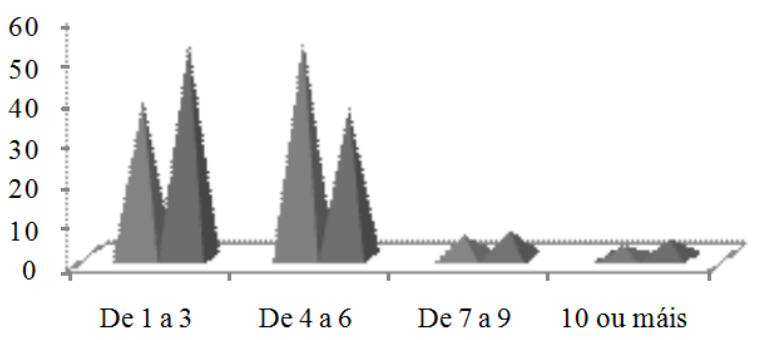

Figura 7. Número de persoas subordinadas (Directoras/es)

\section{Discusión}

A incorporación tardía das mulleres ao mercado laboral provoca unha similitude de representación deste grupo nas idades máis temperás con respecto aos seus compañeiros varóns, cunha clara diminución de presenza feminina a partires dos 45 anos.

A formación académica de mulleres e homes mostra tendencias ben diferenciadas; a medida que ascendemos no nivel académico a porcentaxe de mulleres mellor formadas aumenta de xeito significativo con respecto aos seus compañeiros varóns.

Existe un desequilibrio na distribución de mulleres e homes nos distintos postos de responsabilidade, a pesar 
de que elas contan cunha maior formación académica que os seus compañeiros.

Ocupando un mesmo posto de traballo as mulleres perciben menos ingresos que os homes. Tendo en conta que o Nivel I se vincula cuns maiores ingresos, mais da metade das mulleres teñen un nivel VII ou superior, o dobre que os seus compañeiros varóns. Esta situación agudízase a medida que ascendemos nos postos de responsabilidade.

A incorporación tardía da muller no mundo da banca tamén se reflexa na antigüidade de unhas e outras dentro da organización. A maioría das mulleres que ocupan postos de dirección ou subdirección incorporáronse á empresa nos últimos 20 anos. Tamén destacar que as mulleres lideran grupos de persoas máis pequenos que os seus compañeiros.

Os resultados obtidos móstrannos que homes e mulleres comparten un mesmo espazo laboral pero non o fan de forma equitativa, xa que a maioría das oficinas están xestionadas por homes e, ademais, as mulleres necesitan maior formación e tempo para alcanzar un posto de responsabilidade.

\section{Referencias}

Barberá, E., Ramos, A. eSarrió, M. (2000). Mujeres directivas ante el tercer milenio: el proyecto NOWDI XXI. Papeles del Psicólogo, 75, 46-52.

Echevarría, C. e Larrañaga,M. (2004).La igualdad entre mujeres y hombres: Una asignaturapendiente. CIRIEC- España, 50, 11-35.

Lei 16/1976 de 8 de abril, de Relacións Laborais. «BOE» núm. 96, de 21 de abril de 1976, páginas 7894 a 7902.

Osca, A e López-Sáez, M. (1994). Desarrollo de carrera y género. Factores que influyen en las diferencias entre hombres y mujeres. Revista dePsicología del Trabajo y de las Organizaciones, 28, 73-86.

Valcárcel, A. (1997). La política de las mujeres, Cátedra, Col. Feminismos, Madrid. 